\title{
Produção e avaliação de um aplicativo móvel para ensino de química ambiental
}

Production and evaluation of a mobile application for environmental chemistry teaching

\author{
Rogério Sousa Estevam ${ }^{1}$ \\ Simone de Fátima Pinheiro Pereira ${ }^{2}$ \\ Davis Castro Santos ${ }^{3}$ \\ Hemilton Cardoso Costa ${ }^{4}$
}

\section{Resumo}

O Quiz Ambiental é um software de celular que foi desenvolvido e testado com o objetivo de avaliar seu uso como um produto educacional no ensino de ciências ambientais. 0 aplicativo apresenta um formato de perguntas e respostas, com questões de múltipla escolha de diferentes níveis de dificuldade, aplicado a professores e estudantes no município de Barcarena - PA. Foi observado o envolvimento e a participação tanto dos alunos, quanto dos professores, durante a execução das atividades relacionadas ao uso desta ferramenta. Os resultados demonstraram que o software proposto, pode ser um aliado no processo de construção de conhecimentos no ensino de química ambiental.

Palavras chave: aplicativo android; aprendizagem; ciências ambientais.

\section{Abstract}

The Environmental Quiz is a cell phone software that was developed and tested to evaluate its use as an educational product in environmental science education. The application presents a question and answer format, with multiple-choice questions of different levels of difficulty, applied to teachers and students in the municipality of Barcarena - PA. It was observed the involvement and participation of both students, and teachers, during the execution of activities related to the use of this tool. The results showed that the proposed software could be an ally in the process of building knowledge in the teaching of environmental chemistry.

Keywords: android application; learning; environmental sciences.

\footnotetext{
${ }^{1}$ Universidade Federal do Pará | roger_sousaestevam@hotmail.com

${ }^{2}$ Universidade Federal do Pará | simonefp@gmail.com

${ }^{3}$ Universidade Federal do Pará | davisquimica@gmail.com

${ }^{4}$ Universidade Federal do Pará | hemiltoncosta@yahoo.com.br
} 


\section{Introdução}

A utilização de instrumentos lúdicos, como os jogos, no ensino das ciências ambientais, desperta nos alunos a busca por superação de suas limitações quanto aos conhecimentos técnicos, proporcionando-Ihes satisfação à medida que estas são ultrapassadas tornando o aprendizado mais dinâmico e divertido (RASZEJA, 2013; MELO et al., 2019).

No trabalho desenvolvido por Liao (2019), foi possível identificar que o jogo pode ser uma atividade que promove grande entusiasmo, exigindo compreensão do conteúdo e raciocínio comparativo rápido, estimulando o pensamento lógico e a inteligência, mostrando-se uma ferramenta instrucional que promove o desenvolvimento cognitivo, físico e social dos estudantes.

Diante disso, o grande desafio dos educadores é tornar o ensino concatenado com os interesses e necessidades práticas dos alunos. A partir desta percepção, é notória a necessidade entre ações práticas e teóricas no processo de ensino-aprendizagem, que auxiliem o processo educacional (SILVA et al., 2018).

Tradicionalmente, as metodologias de ensino eram caracterizadas com ênfase no conteúdo transmitido, através de aulas expositivas que exploravam do aluno a capacidade de memorização de informações, fórmulas, nomes e de conhecimentos fragmentados da realidade, sem, contudo, apresentar um significado prático para os alunos (SOARES et al., 2017).

No entanto, a Organização das Nações Unidas para a Educação, a Ciência e a Cultura (UNESCO), em seu guia publicado em 2013, afirma que a aprendizagem pode ocorrer de várias formas, por meio do uso de aparelhos móveis, com suporte para acessar recursos educacionais, interagindo com outras pessoas dentro ou fora das salas de aula.

Dentre esses aparelhos móveis, os smartphones apresentam maior frequência de uso, segundo trabalho desenvolvido por Teixeira (2016). O autor afirma que os jovens da geração atual são considerados "nativos digitais", por conta do ambiente tecnológico atual, composto por jogos em rede, aplicativos, acesso à internet.

Esse novo contexto, tem impulsionado o desenvolvimento de aplicativos de celular, com fins educacionais. Fantini et al. (2011), evidenciam que o número de jogos para a educação ambiental vem aumentando, todavia, a utilização deste recurso ainda é limitada, em alguns casos por razões de infraestrutura, como ausência de um laboratório de informática ou mesmo de um ponto de acesso à internet, ou por razões de conhecimento e utilização dessas ferramentas, por parte dos professores.

É importante considerar, durante a elaboração de um jogo digital, que para que essa ferramenta didática possa auxiliar professores no processo construção de conhecimentos relacionados à educação ambiental, ela não pode simplesmente apresentar um caráter lúdico, recreativo, mas deve ser integrada com o conteúdo apresentado em sala de aula (BITANTE et al., 2016).

Alguns estudos apontam que por meio da utilização do lúdico, é possível que se criem metodologias baseadas no processo de socialização, criatividade, planejamento estratégico e desenvolvimento cognitivo dos alunos, permitindo que o processo de construção do conhecimento seja desenvolvido de forma descontraída (SCHNORR et al., 2017).

Klein et al. (2019), observaram em seus trabalhos sobre educação ambiental por meio da ludicidade, que a utilização desta ferramenta associada aos conhecimentos científicos, pode vir a contribuir para um processo de aprendizagem prazeroso, trazendo momentos de felicidade para os educandos, em diferentes etapas da vida. 
Em seu estudo sobre as tecnologias educacionais para educação ambiental, Guerra (2010) identifica que muitos professores reclamam da falta de acesso a recursos didáticos de qualidade em meio digital, além da falta de capacitação docente, principalmente no que diz respeito ao uso destas ferramentas, visto que muitos docentes trazem uma lacuna, em sua formação inicial, relacionada à utilização de tais tecnologias.

Um ponto chave na utilização deste tipo de ferramenta está relacionado à questão da interatividade que estes jogos devem apresentar. Galvão e Cohen (2016) observaram em suas análises e testes, com os principais aplicativos voltados para questões sustentáveis, que os usuários desta tecnologia não querem ser passivos durante seu uso, mas buscam interagir, sentindo-se parte ativa no jogo.

Portanto, ao se levantar essas informações, a ideia de se utilizar um jogo que pudesse motivar e dinamizar as aulas foi concebida considerando-se a realidade dos jovens no contexto atual. Tal contexto está diretamente ligado ao ambiente tecnológico, principalmente por meio do uso de dispositivos móveis, como tablets e smartphones.

Logo, desenvolveu-se um jogo, no formato de aplicativo de celular, apresentando questões relacionadas a problemas ambientais, como chuva ácida, poluição da água, efeito estufa, entre outros, que podem ser abordados de forma transversal e interdisciplinar em diferentes disciplinas do ensino médio, como a química, a biologia e a geografia.

\section{Metodologia de pesquisa}

O aplicativo Quiz Ambiental foi desenvolvido através da plataforma de criação de aplicativos móveis APPY PIE, a qual permite que sejam produzidas soluções compatíveis com as plataformas Android, IOS, Windows Phone e BlackBerry. Esta plataforma foi projetada para dar suporte a pessoas com ou sem experiência em linguagens de programação.

Existem diferentes planos para o desenvolvimento destes softwares e no plano gratuito, já é possível que se desenvolvam aplicações, basta que você acesse sua página inicial, clique no ícone com a opção comece agora e aí é só seguir as orientações do próprio site para a elaboração de seu primeiro aplicativo.

O Quiz Ambiental conta com uma tela inicial que apresenta ícones sobre o aplicativo, um link para um website onde os estudantes poderão ter acesso a materiais de apoio para estudos relacionados às ciências ambientais, além do ícone de agendamento, para programar o dia, horário em que irá jogar e o início do jogo, conforme Figura 1.

Após o desenvolvimento do aplicativo, ele foi testado e validado de forma experimental com alguns professores e alunos. Feito isso, partiu-se para sua aplicação prática junto aos sujeitos envolvidos nesse projeto de pesquisa. Ao todo, 20 professores participaram desse trabalho, somados aos 105 alunos das duas instituições envolvidas.

A primeira, uma instituição de ensino profissionalizante da rede privada, localizada no município de Barcarena - PA, da qual participaram alunos e professores de cursos de qualificação profissional básica, de diferentes áreas de formação. Sendo 37 alunos de uma turma de aprendizagem industrial básica na área administrativa, aqui identificada como turma A, 20 alunos de uma turma de aprendizagem industrial básica da área elétrica, aqui identificada como turma B e 15 alunos da turma de aprendizagem industrial básica da área metalúrgica, identificada como turma $C$, sendo que todos os alunos possuíam idade média entre 18 a 22 anos. 


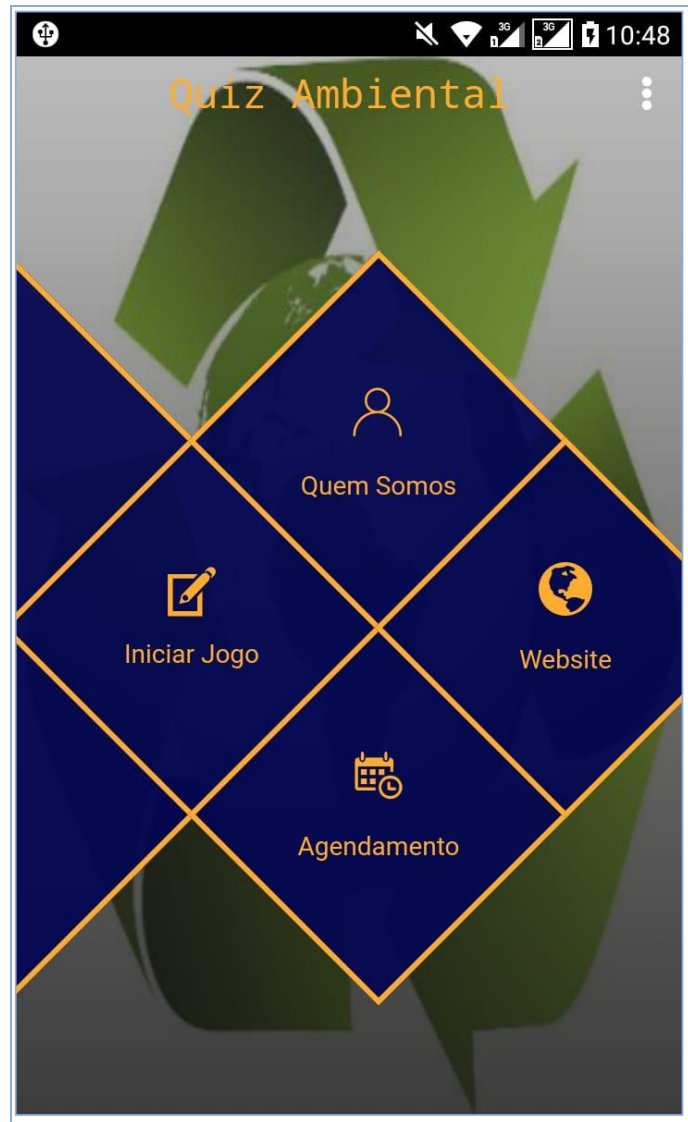

Figura 1: Tela inicial do aplicativo

A segunda instituição participante foi uma escola de educação básica da rede pública estadual, também localizada no município de Barcarena - PA, que também contou com a participação de professores e alunos. Ao todo 33 alunos de uma turma de segundo ano do ensino médio, identificada como turma D. Os alunos tinham idades entre 15 e 17 anos.

Definidos os sujeitos, procedeu-se a aplicação de um questionário diagnóstico, adaptado de Santos (2010), com professores e alunos. No questionário aplicado aos professores (material suplementar), buscou-se levantar o perfil de atuação, o tempo de experiência, o tipo de instituição onde trabalham a formação acadêmica, entre outros questionamentos.

O questionário diagnóstico aplicado junto aos alunos (material suplementar) buscou identificar quais conhecimentos prévios eles detinham sobre problemas relacionados a questões ambientais. Também foram introduzidas questões presentes no aplicativo desenvolvido, que depois eles deveriam responder novamente.

A proposta de utilização do jogo se deu por meio da formação de equipes, que tinham que responder inicialmente dez questões, sendo eliminada a equipe com menor pontuação, formando de certa forma um ranking das equipes com melhor desempenho. Essa informação era coletada em tempo real, por meio do painel de controle disponível no site onde o aplicativo estava hospedado, permitindo o gerenciamento de todas as ações dos usuários do aplicativo.

Após a aplicação do jogo, os alunos responderam a um questionário (material suplementar) com perguntas direcionadas a finalidade do uso preponderante do celular, além de outras relacionadas à utilização do aplicativo como ferramenta de ensino. 


\section{Resultados}

No levantamento junto aos professores, por meio de um questionário aberto, observou-se que estes ainda atuam de forma tradicional, por meio de aulas expositivas, corroborando o observado por Teixeira (2016) e Santos (2016), e que o ensino hoje ainda é predominantemente técnico, havendo contextualização dos conhecimentos, todavia, não comtemplando efetivamente as necessidades contemporâneas da educação.

Segundo Souza (2017), para que o processo de interatividade com o material educacional utilizado em sala de aula aconteça, é necessário que o docente seja o principal agente de mediação e motivação, e para que tal fato ocorra esse docente deve estar atualizado e em parceira com o sistema educacional, que também deve ter uma visão contemporânea sobre a utilização dessa ferramenta tecnológica.

A análise dos dados sobre a utilização de atividades lúdicas por parte dos professores durante suas aulas demonstrou que 55 \% dos professores já aplicam alguma atividade lúdica junto aos seus alunos, sejam jogos, dinâmicas, entre outras. Todavia, entre os entrevistados, apenas sete professores possuíam algum tipo de aplicativo relacionado à disciplina que ministram.

Apesar de se ter observado durante a pesquisa, que o número de professores que possuíam aplicativos instalados ainda é baixo, percebemos também que os professores que instalaram o Quiz Ambiental, tiveram uma boa aceitação desse produto educacional e vários deles pediram permissão para utilizá-lo em suas aulas.

Essa informação foi extremamente importante, pois assim como Silva (2015) e Magalhães (2019), também inferimos que a aplicação desse produto educacional, é um objeto potencialmente significativo para os professores que se dispuseram a trabalhar com ele em suas aulas, criando um ambiente de aprendizado descontraído, dinâmico e que propiciou maior interação entre os alunos e destes com os professores.

Essa informação de certa forma representa uma mudança na atuação desses profissionais, buscando novas formas de ensinar. Para Moraes (2016), os docentes buscam acompanhar as inovações no contexto educacional, que colaborem na compreensão dos conteúdos de forma dinâmica, o que também foi observado nesta pesquisa, conforme mostrado a partir da Figura 2.

Nele observamos que somada às metodologias tradicionais, como aulas expositivas, os professores também fazem uso de outras estratégias de ensino-aprendizagem, como debates, dinâmicas, filmes, visitas técnicas e a utilização de jogos educativos.

Os dados de desempenho e avaliação dos alunos, obtidos por meio do produto educacional, foram plotados em gráficos, representando um momento e antes e após a aplicação do Quiz, de modo a se analisar comparativamente esses resultados.

Ao analisarmos o desempenho das quatro turmas que participaram das atividades desenvolvidas neste projeto de pesquisa, por meio da figura 3, antes e após a aplicação do produto educacional, percebemos que elas apresentaram uma média de acertos, próxima uma das outras, algumas com valores percentuais quase iguais, como no caso da turma B e da turma D, antes do jogo.

Esses resultados demonstram, assim como Silva (2015) e Magalhães (2019), observaram em seus trabalhos com aplicativos no formato de Quiz, para o ensino da física, que após a utilização desta tecnologia educacional, o desempenho das turmas melhorou. Com o Quiz Ambiental, as turmas tiveram uma variação entre 42 a $61 \%$ antes do jogo e de 58 a 74 \% 
após o jogo, com algumas pequenas diferenças entre si, onde a turma B obteve a maior evolução, com aproximadamente $20 \%$ de diferença.

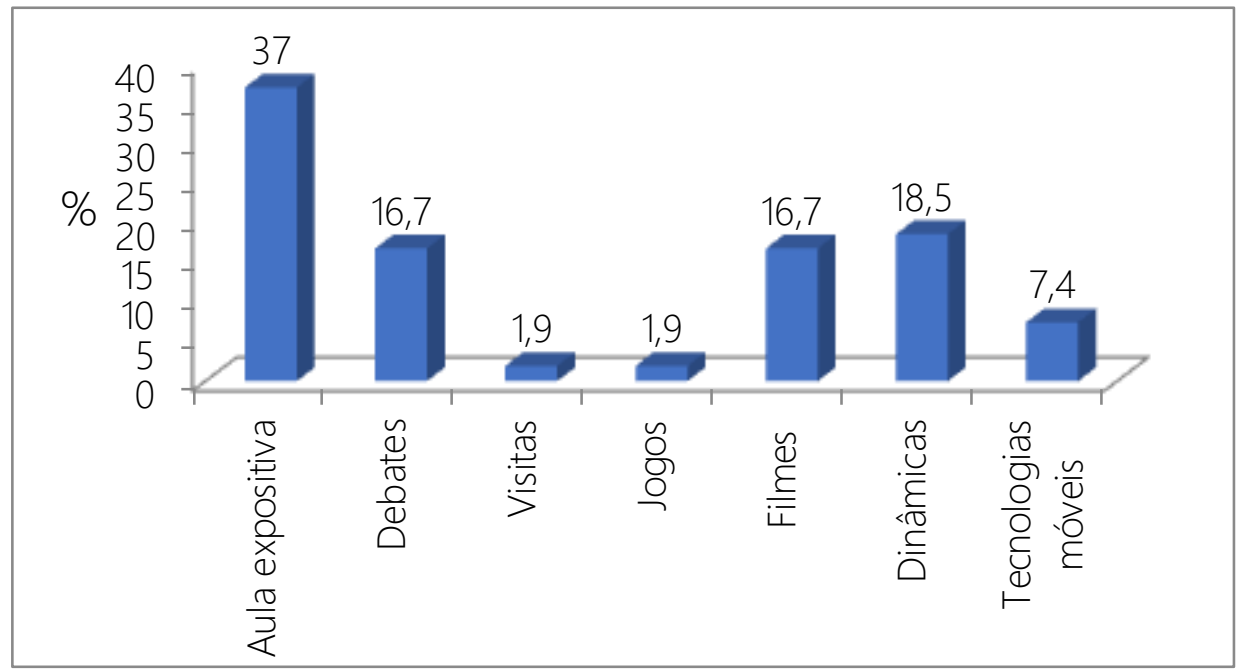

Figura 2: Principais metodologias utilizadas pelos professores

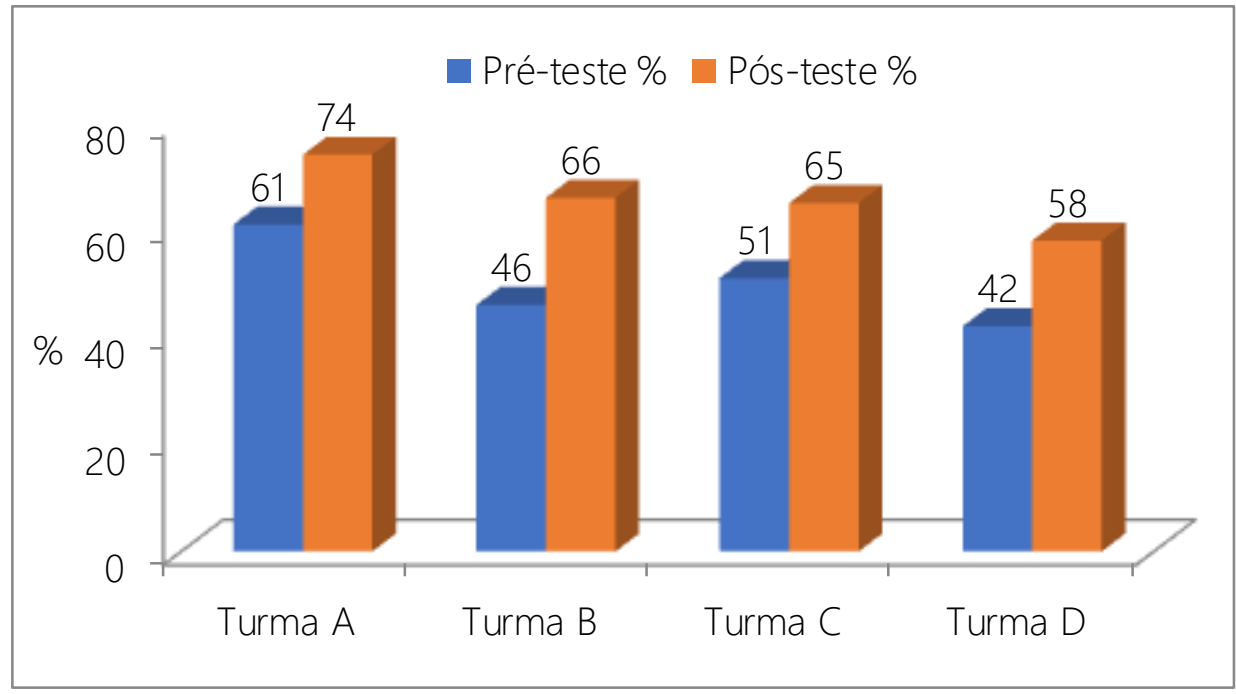

Figura 3: Desempenho das turmas antes e após a aplicação do jogo.

Teixeira (2016) em seu trabalho com aplicativo Física in Mãos, para o ensino de assuntos relacionados aos conceitos sobre gravitação, também percebeu que os alunos envolvidos em sua pesquisa, obtiveram desempenho superior, após a aplicação do Quiz, o que segundo o autor, deve-se ao fato de esta ser uma metodologia de ensino menos anacrônica com a realidade dos alunos.

Ferbek e Vila (2013) constataram por meio dos trabalhos com o aplicativo EcoQuiz, que $87 \%$ dos alunos que participantes do projeto desenvolvido por eles, declararam que o aprendizado através do uso desta ferramenta, pode se tornar mais atrativo e motivador, quer seja pelo conteúdo abordado ou pela metodologia utilizada. 
Esses dados ajudam a avaliar a possível utilização do aplicativo, como ferramenta didático-pedagógica, auxiliando professores e alunos no processo de construção e solidificação de conhecimentos relacionados a problemas ambientais e ao ensino das ciências ambientais.

Para realização da avaliação do aplicativo de celular, Quiz Ambiental, ao final dos trabalhos os alunos responderam a um questionário avaliativo do jogo. Neste, havia algumas perguntas que foram adaptadas de Teixeira (2016), com abordagens sobre a forma de utilização do celular conforme Figura 4.

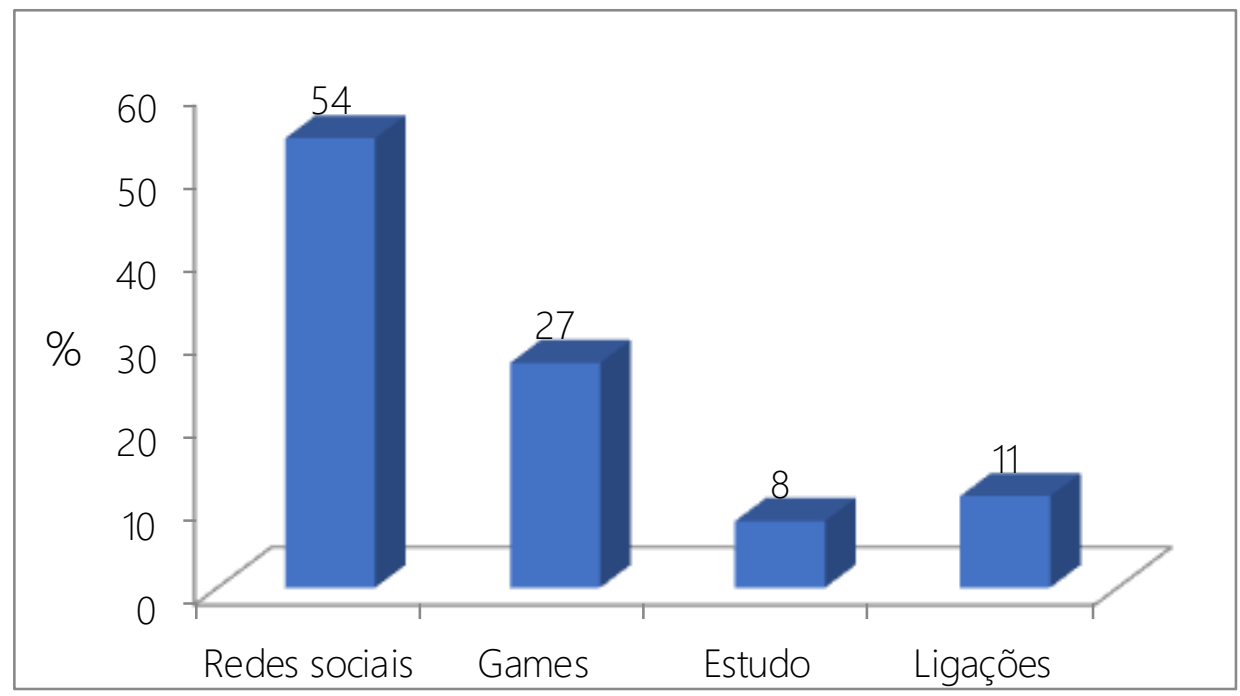

Figura 4: Meios e finalidade de uso do celular.

Essa informação demonstrou que 54 \% dos alunos envolvidos na pesquisa, utilizam os seus smartphones principalmente com a finalidade de acesso e interação as redes sociais, seguido de $27 \%$ dos que o utilizam com a finalidade de uso recreativo, por meio dos jogos.

Nessa nova realidade, o professor deve buscar estratégias que estejam concatenadas com os alunos, por meio de trabalhos como o de Carvalho (2014), que desenvolveu um blog sobre educação ambiental, utilizando essa ferramenta tecnológica no ensino fundamental, para auxiliar professores e alunos.

Costa (2017) concluiu após a utilização do aplicativo Scrtach, que os docentes devem buscar ferramentas que sejam contemporâneas à realidade dos estudantes, mesmo diante das dificuldades encontradas, como as de ordem estrutural, a exemplo o acesso a pontos de internet ou mesmo a falta de um laboratório de informática na escola.

Pontes et al. (2017), durante seus trabalhos, por meio do jogo eletrônico LINO, perceberam que a utilização desse caminho lúdico tornou a construção de conhecimentos sobre educação ambiental, mais agradável e dinâmica, além de contribuir para maior interação entre os alunos e destes com o professor.

Vale ressaltar que cada docente possui suas próprias estratégias para abordar as temáticas ambientais junto aos seus alunos. Caso esse professor busque um caminho inovador, as novas tecnologias educacionais podem ajudá-lo nesse processo, por meio um ambiente de ensino que está inserido nessa realidade de aplicativos para celulares e jogos eletrônicos, que podem estimular o aprendizado além de sensibilizar os estudantes para problemas ambientais (BITANTE et al., 2016). 
Outra informação levantada ao final dos trabalhos, diz respeito à capacidade de motivação promovida tanto pelo aplicativo, quanto pela forma que o professor utilizou esta ferramenta durante as atividades. Entre os alunos entrevistados, 83 \% deles afirmaram que o Quiz Ambiental foi uma ferramenta motivadora, Figura 5, na construção do conhecimento relacionado às ciências ambientais.

Apesar de ser num formato de Quiz, com perguntas e respostas, o professor que vir a utilizá-lo, pode programar que as atividades sejam feitas em equipe ou de forma individual. Essa flexibilidade do jogo permite que o professor planeje as diferentes formas de se aplicar o jogo com a mesma turma, verificando a que desperta maior interesse e participação dos alunos.



Figura 5: Capacidade de motivação do aplicativo

Ainda dentro do processo de avaliação do aplicativo, os alunos foram questionados sobre a ampliação de seus conhecimentos relacionados a problemas ambientais, principal temática abordada nas questões que compõem o Quiz (Figura 6). Dos entrevistados, 92 \% afirmaram que sim, que o aplicativo trouxe novos conceitos e informações sobre esses tipos de problemas, no entanto de forma descontraída, como observado por Teixeira (2016).

Esse foi um dos pontos chave no momento da elaboração deste produto educacional, tornar o ensino descontraído, dinâmico, interativo, sem, contudo perder a função educadora, promovendo a construção de conhecimentos sobre temáticas ambientais, contribuindo para a prática pedagógica e auxiliando no desenvolvimento cognitivo dos alunos (NETO \& MORADILLO, 2017).

Outra vantagem no uso de aplicativos de celulares, como ferramenta pedagógica utilizada para construção de conhecimentos, reside no fato de que como esse produto educacional, em algumas situações fica hospedado em um dashboard ou mesmo em um blog, o professor terá acesso ao relatório de desempenho dos alunos em tempo real, permitindo que ele já informe a eles, o resultado da atividade desenvolvida em sala, em um menor intervalo de tempo (JÚNIOR, 2017). 




Figura 6: Aquisição de novos conhecimentos

Além dos resultados positivos, outro dado muito importante diz respeito aos comentários e indagações feitas, pelos estudantes. Foram feitas perguntas se eles poderiam jogar mais de uma vez, ou ainda relatos de que alguns deles tinham feito uma revisão dos assuntos vistos no aplicativo e teriam jogado novamente, para avaliar a evolução no resultado individual. Essas informações apontam para a necessidade de inovação por parte dos professores, desenvolvendo estratégias metodológicas que, estejam dentro do contexto tecnológico dessa nova geração, que vivencia com maior frequência o mundo virtual dos jogos, e a partir de então utilizar a tecnologia a favor da construção do conhecimento (TEIXEIRA, 2016).

Algumas críticas também foram feitas pelos alunos, sobre o produto educacional. Dentre elas, a mais evidente era que os alunos esperavam que o aplicativo tivesse mais ícones gráficos. Essa modificação foi desenvolvida e na versão atualizada do produto, novas imagens e outros ícones gráficos foram adicionados.

As críticas são de extrema importância durante o processo de teste e validação do aplicativo, todavia, no momento da elaboração e programação do jogo, sempre devem estar muito claros, a finalidade e o público alvo dessa aplicação. Outro dado importante na hora de se desenvolver um aplicativo, é que os usuários dessa tecnologia, buscam interatividade e desafios de superação.

\section{Considerações finais}

Na perspectiva, da atuação docente ser fundamentada no processo de construção do conhecimento, de maneira conjunta com os estudantes, o presente estudo desenvolveu e avaliou a utilização do aplicativo de celular Quiz Ambiental, validando sua aplicabilidade como ferramenta de apoio pedagógico.

Foi possível inferir, após a análise dos dados coletados, que a utilização deste aplicativo junto aos envolvidos, contribuiu para a construção de conhecimentos relacionados às problemáticas do meio ambiente, de forma descontraída e dinâmica, auxiliando-os na construção do saber científico.

Em razão da versatilidade constatada no uso do software durante os testes, docentes participantes enfatizaram sua potencialidade como ferramenta de ensino, visto que 
poderiam desenvolver seus próprios aplicativos, com questões relacionadas aos conteúdos de suas disciplinas. No caso dos estudantes, o maior relato era sobre a possibilidade de reiniciar as atividades do jogo, podendo avaliar a evolução deles sobre os conceitos abordados.

Em um aspecto global sobre sua utilização, com as informações coletadas no trabalho, podemos concluir que este produto educacional, quando bem planejado pelo docente e com uma infraestrutura mínima como ponto de acesso à internet, poderá ser um aliado na construção do conhecimento, auxiliando professores e alunos.

\section{Agradecimentos}

O presente trabalho foi realizado com apoio da Coordenação de Aperfeiçoamento de Pessoal de Nível Superior - Brasil (CAPES) e do Programa de Pós-graduação em Rede Nacional para Ensino das Ciências Ambientais PROFCIAMB-UFPA. Também gostaríamos de agradecer aos alunos e professores que participaram da pesquisa, ao Programa de Pósgraduação em Química PPGQ-UFPA e ao Laboratório de Química Analítica e Ambiental LAQUANAM-UFPA.

\section{Referências}

BITANTE, A. P.; FARIA, A. C.; GASPAR, M. A.; PASCUAL, J. V. I.; DONAIRE, D. A. Impactos da tecnologia da informação e comunicação na aprendizagem dos alunos em escolas públicas de São Caetano do Sul. Holos, v. 8, p. 281-222, 2016.

CARVALHO, D. A. Blog de educação ambiental: ferramenta tecnológica para o processo de ensino-aprendizagem no ensino fundamental. Dissertação (Mestrado em Educação) Programa de Pós-Graduação Mestrado Profissional em Ensino de Ciências da Saúde e Meio Ambiente do Centro Universitário de Volta Redonda, Volta Redonda, 2014, 75p.

COSTA, T. R. Uso do aplicativo Scratch no ensino de ciências: uma abordagem na formação de professores de Física. Dissertação (Mestrado em Educação) Programa de Pós-Graduação Mestrado Profissional em Ensino de Ciências e Matemática da Universidade Federal do Acre, Rio Branco, 2017. 73 p.

FANTINI, V.; COSTA, E. R.; MELO, C. I. Os jogos virtuais para a educação ambiental no ensino fundamental. Tecnologias na Educação, v. 3, n. 1, p. 1-10, 2011.

FERBEK, G. J. V.; VILA, P. S. Desenvolvimento de um aplicativo visando à educação ambiental. Simpósio de Excelência em Gestão e Tecnologia, RJ: SEGET, 2013, p. 1-7.

GALVÃO, M. F. G.; COHEN, M. Aplicativos verdes: uma análise contextualizada de programas para celulares (sistema iOS) votados para ações sustentáveis. Encontro Internacional sobre Gestão Empresarial e Meio Ambiente, SP: ENGEMA, 2016, p. 3-16.

GUERRA, A. F. S. As tecnologias educacionais na formação em educação ambiental para a sustentabilidade. Diálogo Educacional, v. 10, n. 31, p. 561-579, 2010.

JÚNIOR, W. F. O uso de dispositivos móveis em sala de aula em uma perspectiva sóciocomunitária. Dissertação (Mestrado em Educação) - Programa de Pós-Graduação em Educação do Centro Universitário Salesiano de São Paulo, Americana, 2017. 101 p. 
KLEIN, C. L.; LOCATELLI, A.; ZOCH, A. N. A educação ambiental por meio da ludicidade: uma proposta didática. Revista de Educação em Ciências e Matemática, v. 15, n. 33, Jan-Jun. 2019. p. 219-234.

LIAO, C.-W.; CHEN, C.-H.; SHIH, S.-J. The interactivity of video and collaboration for learning achievement, intrinsic motivation, cognitive load, and behavior patterns in a digital gamebased learning environment. Computers \& Education, v. 133, p. 43-55, 2019.

MAGALHÃES, R. A. P.; PINHEIRO, P. S. B.; SERUFFO, M. C. R. Desenvolvimento e avaliação de um jogo para auxílio do processo de ensino e aprendizado: Um estudo de caso. Research, Society and Development, v. 8, n. 7, p. 1-23, 2019.

MELLO, C. M. G.; RODRIGUES, D. C. G. A.; PEREIRA, A. Jogo cooperativo como uma proposta lúdica no ensino de ciências ambientais - por uma ética do cuidado. Revista Eletrônica Ludus Scientiae - (RELUS), v. 3, n. 2, p. 53-68, 2019.

MORAES, T. S. Estratégias inovadoras no uso de recursos didáticos para o ensino de ciências e biologia. Dissertação (Mestrado em Gestão) - Programa de Pós-Graduação Mestrado Profissional Gestão e Tecnologias Aplicadas à Educação da Universidade do Estado da Bahia, Salvador, 2016. 135 p.

NETO, H. S. M..; MORADILLO, E. F. O jogo no ensino de química e a mobilização da atenção e da emoção na apropriação do conteúdo científico: aportes da psicologia histórico-cultural. Ciênc. Educ., v. 23, n. 2, p. 523-540, 2017.

PONTES, A. N.; MENDES, I. F.; TOMAZELA, M. G. J. M. Lino: jogo eletrônico para auxiliar na educação ambiental de crianças em idade escolar. Thema, v. 14, n. 4, p. 136-148, 2017.

RASZEJA, A. "Batalha dos elementos". Influência do jogo didático na aprendizagem em sala. Trabalho de Conclusão de Curso (Monografia) - Curso de Especialização em Ciências, Universidade Tecnológica Federal do Paraná, Medianeira, PR, 2013. 74 p.

SANTOS, L. M. M. Elaboração de material paradidático para educação ambiental com ênfase em atividades lúdicas. Dissertação (Mestrado em Ensino de Ciências e Matemática) Programa de Pós-Graduação da Pontifícia Universidade Católica de Minas Gerais, Belo Horizonte, 2010. 88 p.

SANTOS, T. S. Tecnologia e educação: o uso de dispositivos móveis em sala de aula. Monografia (Especialização em Ensino e Tecnologia) - Programa de Pós-Graduação em Ciências Humanas da Universidade Tecnológica Federal do Paraná, Londrina, 2016. 70 p.

SCHNORR, S. M.; RODRIGUES, C. G.; ISLAS, C. A. Uso das tecnologias contemporâneas como recurso pedagógico para as aulas de ciências. Experiências em Ensino de Ciências, v. 12, n. 3, p. 31-42, 2017.

SILVA, R. L. S.; SOUZA, G. M.; SANTOS, B. F. Questionamento em aulas de Química: Um estudo comparativo da prática pedagógica em diferentes contextos sociais. Revista Brasileira de Pesquisa em Educação em Ciências, v. 18, n. 1, p. 69-96, 2018.

SILVA, F. U. Uso de Quiz em smartphones visando o auxílio na aprendizagem de física no ensino médio. Dissertação (Mestrado em Ensino de Física) - Programa de Mestrado Profissional de Ensino de Física do Instituto Federal de Educação, Ciência e Tecnologia do Rio Grande do Norte, Natal, 2015. 132 p. 
SOARES, E. L.; VIÇOSA, C. S. C. L.; TAHA, M. S.; FOLMER, V. A presença do lúdico no ensino dos modelos atômicos e sua contribuição no processo de ensino aprendizagem. Revista Góndola, Enseñanza y Aprendizaje de las Ciencias, v. 12, n. 2, pag. 69-80, 2017.

SOUZA, S. H. Celular em sala de aula: de vilão a solução - construção de atividades no contexto CTS. Dissertação (Mestrado no Ensino de Ciências) - Programa de Mestrado Profissional em Ensino de Ciências do Instituto de Ciências Exatas e Biológicas da Universidade Federal de Ouro Preto, Ouro Preto, 2017. 132 p.

TEIXEIRA, R. T. M. Construção e uso de um aplicativo para smartphones como auxílio ao ensino de física. Dissertação (Mestrado em Ensino de Física) - Programa de Mestrado Profissional de Ensino de Física do Instituto Federal de Educação, Ciência e Tecnologia do Rio Grande do Norte, Natal, 2016. 131 p.

UNESCO. Diretrizes de políticas para a aprendizagem móvel. 2013. Disponível em <http:// http://www.bibl.ita.br/UNESCO-Diretrizes.pdf Acesso em 08/08/2020. 